Religion, suicide and psychological distress

The Role of Religion on Suicidal Behavior, Attitudes and Psychological Distress in University Students: A Multinational Study

Mehmet Eskin ${ }^{1,17}$, Senel Poyrazli ${ }^{2}$, Mohsen Janghorbani ${ }^{3}$, Mauro Giovanni Carta ${ }^{4}$, Ulrich S. Tran $^{5}$, Anwar Mechri ${ }^{6}$, Motasem Hamdan ${ }^{7}$, Hani Nawafleh ${ }^{8}$, Jian-Min Sun ${ }^{9}$, Chris Flood ${ }^{10}$, Kouichi Yoshimasu ${ }^{11}$, Omar Kujan ${ }^{12,13}$, Khouala Aidoudi ${ }^{6}$, Seifollah Bakhshi ${ }^{3}$, Hacer Harlak $^{14}$, Maria Francesca Moro ${ }^{4}$, Yousef Khader ${ }^{15}$, Louise Phillips ${ }^{10}$, Amira Shaheen ${ }^{16}$, Shahama Taifour $^{12}$, Kanami Tsuno ${ }^{11}$, Martin Voracek ${ }^{5}$

${ }^{1}$ Adnan Menderes University, Faculty of Medicine, Department of Psychiatry, Aydin, Turkey

${ }^{2}$ School of Behavioral Sciences and Education, Pennsylvania State University-Harrisburg,

Middletown, Pennsylvania, USA

${ }^{3}$ School of Public Health, Isfahan University of Medical Sciences, Isfahan, Iran

${ }^{4}$ Department of Public Health, Clinical and Molecular Medicine, University of Cagliari, Italy

${ }^{5}$ Department of Basic Psychological Research and Research Methods, School of Psychology, University of Vienna, Austria

${ }^{6}$ Department of Psychiatry, University hospital of Monastir, Monastir, Tunisia

${ }^{7}$ School of Public Health, Al-Quds University, Jerusalem, Palestine

${ }^{8}$ Princess Aisha Faculty of Nursing and Health Sciences, Al-Hussein Bin Talal University,

Ma'an, Jordan

${ }^{9}$ Department of Psychology and School of Labor and Human Resources, Renmin University of China, Beijing, China

${ }^{10}$ School of Health Sciences, City University of London, UK

${ }^{11}$ Department of Hygiene, School of Medicine, Wakayama Medical University, Wakayama, Japan

${ }^{12}$ Department of Oral and Maxillofacial Sciences, Al-Farabi College for Dentistry and Nursing, Riyadh, Saudi Arabia

${ }^{13}$ School of Dentistry/Oral Health Center of Western Australia, University of Western Australia, Perth, Australia

${ }^{14}$ Adnan Menderes University, Faculty of Arts and Sciences, Department of Psychology, Aydin, Turkey

${ }^{15}$ Department of Community Medicine, Public Health and Family Medicine, Faculty of Medicine, Jordan University of Science \& Technology, Irbid, Jordan

${ }^{16}$ Faculty of Medicine and Health Sciences, An-Najah National University, Nablus, West Bank, Palestine

${ }^{17}$ To whom correspondence should be addressed at Department of Psychiatry, Faculty of Medicine, Adnan Menderes University, Aydin, Turkey; e-mail: meskin@adu.edu.tr or meskin48@gmail.com 
Religion, suicide and psychological distress

\title{
The Role of Religion on Suicidal Behavior, Attitudes and Psychological Distress in University Students: A Multinational Study
}

\begin{abstract}
The purpose of this study was to determine the association of religion to suicidal behavior, attitudes and psychological distress in 5572 students from 12 countries by means of a selfreport questionnaire. Our results showed that an affiliation with Islam was associated with reduced risk for suicide ideation, however affiliating with Orthodox Christianity and no religion was related to increased risk for suicide ideation. While affiliating with Buddhism, Catholic religion and no religion associated with lowered risk for attempting suicide, affiliation with Islam was related to heightened risk for attempting suicide. Affiliation with Hinduism, Orthodox Christianity, Protestantism, Catholicism, other religions and with no religion was associated with decreased risk for psychological distress but those reported affiliating with Islam evinced greater risk for psychological distress. The associations of the strength of religious belief to suicidal ideation and attempts were in the expected direction for most but it had a positive relation in respondents affiliating with Catholicism and other religions. Students reporting affiliation with Islam, Orthodox religion and Buddhism were the least accepting of suicide but they displayed a more confronting interpersonal style to an imagined peer with a suicidal decision. It was concluded that the protective function of religion in educated segments of populations (university students) and in university students residing in Muslim countries where freedom from religion is restricted or religion is normative and/or compulsory is likely to be limited. Our findings suggest that public policies supporting religious freedom may augment the protective function of religion against suicide and psychological distress.
\end{abstract}

Key words: Religion, suicide, psychological distress, attitudes, cross-cultural 
Religion, suicide and psychological distress

\section{Introduction}

A well-established regularity in suicidology is that the rates of suicidal behaviore show large intersocietal variation (Värnik, 2012). The main research variable in this study, religion, has also usually been assumed to be related to the intersocietal variation of suicidal behaviors (Bertolote, \& Fleischmann, 2015). For instance, low suicide rates in persons affiliating with Islam and in nations with predominantly Muslim populations are attributed either to the explicit condemnation of suicide by Islamic scripture (Lester, 2006; Shah, \& Chandia, 2010) or to underreporting (Pritchard, \& Amanullah, 2007). All religions have explicit or implicit sanctions against self-killing with varying degrees of severity (Nelson, Hanna, Houri, \& Klimes-Dougan, 2012).

Religion is a complex but unified system of beliefs, practices and institutions about the sacred (Durkheim, 1976). From an evolutionary perspective it has been argued that religion, as an integral cultural syndrome, has evolved to reduce the fitness costs and improve the fitness benefits of their fellow members at both individual and group levels along with the cultural evolution (Boyer, \& Bergstrom, 2008). According to Purzycki, Haque, and Sosis, (2014), religious systems help to increase adaptive capacities of its believers in a constant social, physical, psychological and existential flux. As a self-reflecting agent, human beings are aware of their own inevitable death and this is a source of existential anxiety. A study by Vail, Arndt, and Abdollahi, (2012) provides empirical support to the view that religious beliefs help people to cope with this existential anxiety.

Suicide is an extreme form of desperation. How does religion protect its believers against such desperation? Colucci and Martin (2008) and Stack (2000) have identified three theoretical formulations about the link between religion and suicide. The first one is the social integration theory (Durkheim, 1897/1951), and the second one is the network theory (Pescosolido, 1990). Both theories argue that religion exercises its protective function against 
Religion, suicide and psychological distress

suicide through developing informal relationships and promoting communal community ties that increase networking and feelings of integration. On the other hand, The third one is the religious commitment theory (Stark, Doyle \& Rushing, 1983; Stack, 2000). It assumes that core religious beliefs opposing suicide prevent individuals from considering suicide as an option during difficult times.

The social integration, network and religious commitment theories outlined above suggest that religion is associated with better mental health. The scientific literature indicates that religion may be a protective factor against diminished psychological well-being (Bonelli, \& Koenig, 2013; Kang \& Romo, 2011). Findings from a recent longitudinal study by Zou, Huang, Maldonado, Kasen, Cohen and Chen, (2014) showed that religious service attendance reduces depressive symptoms significantly. Note that reduced mental health is one of the strongest risk factors for suicidal behavior. Religion is also assumed to be a deterrent against suicidal behavior (Dervic, Oquendo, Grunebaum, Ellis, Burke, \& Mann, 2004; Wu, Wang, \& Jia, 2015). Further, acceptability of suicide is lower in religious than in nonreligious people (Stack, \& Kposowa, 2011), and higher levels of suicide acceptability was found to be associated with contemplating, planning and attempting suicide (Joe, Romer, \& Jamieson, 2007). However, some research including a recent review by Lawrence, Oquendo and Stanley (2015), present a complex picture of the relation between religion and suicidal behavior. Lawrence et al. (2016) concluded that religious affiliation was protective against suicidal attempts and suicide but not against suicidal ideation.

There are two major methodological flaws of the scientific endeavor investigating the link between religion and psychological distress and/or suicidal behaviore. First, most of the previous empirical work on the issue is carried out with samples from industrialized Western nations. Second, except for the work by Sisask et al. (2010) most studies are of ecological nature which includes other confounding variables such as levels of economic development, 
Religion, suicide and psychological distress

education, secularization, etc. Bearing these methodological considerations in mind we tested whether religious affiliation and the strength of one's religious belief were related to nonfatal suicidal behavior, psychological distress, and attitudes towards suicide and suicidal individuals. If so, which religions have a possible relationship? We sought answers to these questions in university students from 12 nations. From a methodological point of view, in order to make cross-cultural comparisons the samples should be comparable to each other. University students are similar in several important aspects such as age, level of education, level of intellectual capacity or media exposure. As a result, we chose to study college students to make samples from different countries as comparable as possible.

\section{Methods}

\section{Participants}

A total of $5572(55.3 \%$ women) university students (mean age $=22.1, \mathrm{SD}=3.5$ years) from 12 countries volunteered to participate in the study. Samples were from the countries that were identified by Inglehart and Baker (2000) as belonging to four culture zones (1) Confucian (China, population $=1,355,692,576$, sample $\mathrm{n}=627$ and Japan, population $=$ $127,103,388$, sample $n=246$ ), (2) Islamic (Iran, population $=80,840,713$, sample $n=1000$; Jordan, population $=7,930,491$, sample $n=436$; Palestine $($ West Bank $)$, population $=$ 2,731,052, sample $n=358$; Saudi Arabia, population $=27,345,986$, sample $n=413$; Turkey, population $=81,619,392$, sample $n=497$ and Tunisia, population $=10,937,521$, sample $n=$ 484), (3) English speaking (UK, population $=63,742,977$, sample $\mathrm{n}=150$ and USA, population $=318,892,103, \mathrm{n}=239$ ) and $(4)$ Catholic (Austria, population $=8,223,062$, sample $\mathrm{n}=627$ and Italy, population $=61,680,122$, sample $\mathrm{n}=471$ ). Participants were recruited from one public university in each country but from two public universities in Jordan and Palestine.

The gender and age distributions differed significantly among countries (gender, $\chi^{2}=$ 294.56, df $=11, \mathrm{p}<0.001 ;$ age, $\mathrm{F}(11,5407)=105.61, \mathrm{p}<0.001)$. There were more female 
Religion, suicide and psychological distress

participants than male participants. However, in the Japanese and Saudi Arabian subsamples, there were more men than women. The US sample was the youngest and the UK sample was the oldest. The number of siblings of students differed significantly between samples $(\mathrm{F}(11$, $5560)=366.45, \mathrm{p}<0.001)$. Jordanian and Palestinian samples had the highest number of siblings and the Chinese had the lowest number of siblings.

Out of the larger data set, so far we have published two papers on the prevalence of suicidal behavior and psychological distress (Eskin et al., 2016a) and attitudes towards suicide and suicidal persons (Eskin et al., 2016b) in which we describe sociodemographic characteristics of participants and the administration of research processes in more detail. In the first paper we found that $29 \%$ of the whole group reported having considered killing themselves, $7 \%$ reported having attempted to kill themselves and more than $1 / 3$ of the sample scored above the conservative GHQ-12 $\geq 5$ cut-off points. Significantly more participants from Austria and the UK reported suicidal ideation while significantly fewer students from China, Italy, Saudi Arabia, Tunisia and Turkey reported suicidal ideation.Significantly more students from Jordan, Palestine, Saudi Arabia, and to some extent from Turkey reported attempting suicide, but significantly fewer participants from Austria, China, Italy, Japan and the US did so. In the second paper we found that the Austrian, the UK, the Japanese and the Saudi Arabian samples were the most accepting of suicide and the Tunisian, the Turkish, the Iranian and the Palestinian samples were the least accepting. The Turkish, the US, the Italian, and the Tunisian samples were the most socially accepting a suicidal friend and the Japanese, the Saudi Arabian, the Palestinian and the Jordanian samples were the least accepting of such a friend. Acceptance of suicide was inversely related to social acceptance for a suicidal friend. We also found in the second paper that individuals were more likely to report more suicial behavior and psychological distress, if they had accepting attitudes towards suicide but rejecting attitudes towards suicidal persons. Further, participants with an accepting attitude to 
Religion, suicide and psychological distress

suicide but rejecting attitude to suicidal persons were more likely to be from countries with high suicide rates and significantly high suicidal behavior reporting samplesIn addition, these individuals were more often from high suicide rate countries and samples than their counterparts.

\section{Instrument}

A self-administered questionnaire was utilized to collect data. The questionnaire included questions about nonfatal suicidal behavior, religious affiliation and strength of religious belief, attitudes towards suicide and suicidal individuals, individualisticcollectivistic value orientations and a measure of psychological distress. In this paper, the associations of religious affiliation and strength of religious belief to nonfatal suicidal behavior, attitudes and psychological distress are reported. (In order to keep a clear focus, the associations of individualism-collectivism values to suicidal behavior, psychological distress and suicidal attitudes will be reported in a separate paper).

\section{Demographics}

In a short demographics questionnaire that was prepared by the lead researcher, students were asked to indicate their gender, age, and the number of siblings they have., and their field of study.

\section{Religious affiliation}

One question (What is your religion?) asked about the participants' religious affiliation based on 15 choices (Buddhism, Hinduism, Roman Catholic, Protestantism, Islam, Christian Orthodox, Judaism, Shintoism, African Religion, I have no religion, Shamanism, Sikhism, Taoism, Mormonism and Other than these). Since few participants in our sample reported having affiliated with African religion $(n=22)$, Shintoism $(n=20)$, Taoism $(n=13)$, Judaism $(n=10)$, Shamanism $(n=4)$, Mormonism $(n=4)$ and Sikhism $(n=3)$, they were merged into the other religion category. Based on the historical claims (For instance 
Religion, suicide and psychological distress

Durkheim's) about the relationship between Protestantism and suicide we have divided Christianity into three (Catholic, Orthodox and Protestant).

Strength of religious belief

Another question (What is the strength of your religious belief?) asked about the strength of their religious belief on a 7-point Likert scale ranging from "None whatsoever (0)" to "Very strong (6)".

\section{Suicidal behavior}

There were five questions about past and current suicidal behavior (Yes $=1$, No $=0$ ):

(1) Have you ever thought of killing yourself? (2) Have you, during the past 12-months, thought of killing yourself? (3) Do you have thoughts of killing yourself right now? (4) Have you ever made an attempt to kill yourself? (5) Have you, during the past 12-months, made an attempt to kill yourself?

Participants responding affirmatively to all or at least one of the first three questions were dichotomized as having suicidal ideation and participants responding affirmatively to both or one of the questions 4 and 5 were dichotomized as having attempted suicide.

\section{Psychological Distress}

The 12-item General Health Questionnaire (GHQ-12; Goldberg, \& Williams, 1988) is the most widely used screening tool for assessing psychological distress. The reliability and the validity of the GHQ-12 are well established (Goldberg, Gater, Sartorius, Ustun, Piccinelli, Gureje, \& Rutter, 1997). The standard method of 0-0-1-1 scoring was used in the study. In this method, a score of 0 was assigned to the first two low stress alternatives and a score of 1 was given to the two high stress alternatives. The method results in individual scores that range from 0 to 12 . The internal consistency reliability of the GHQ-12 in this study was 0.87 with item-total correlations ranging from 0.45 to 0.62 . Goldberg et al., (1997) suggested 
Religion, suicide and psychological distress

varying GHQ-12 cut-off points from a low of 2 to a high of 4 in 15 centers. Therefore, we used three cut-off (GHQ-12 $\geq 3,4,5)$ points in this study.

\section{Attitudes towards suicide}

Twenty-four item Eskin's Attitudes towards Suicide Scale (E-ATSS, Eskin, 1999a; 2004; 2013; Eskin et al., 2016b) with five point Likert type response options ranging from “Completely disagree (1)" to "Completely agree (5)" was used to measure students' attitudes towards suicide. A principle component analysis with varimax rotation extracted six factors: 1. Acceptability of suicide $(\alpha=0.91) ; 2$. Punishment after death $(\alpha=0.93) ; 3$. Suicide as a sign of mental illness $(\alpha=0.94)$; 4. Communicating psychological problems $(\alpha=0.79) ; 5$. Hiding suicidal behavior $(\alpha=0.82)$; 6. Open reporting and discussion of suicide $(\alpha=0.62)$ that explained $73.10 \%$ of the total variance.

\section{Attitudes towards suicidal persons}

Eskin's Social Reactions to Suicidal Persons Scale (E-SRSPS) begins with a short description of "an imagined suicidal close friend" who decides to kill him/herself and share it with participant. By means of 20 possible reactions to this friend, students were asked how they would react or feel on 5-point Likert scales ranging from "Completely disagree (1)" to “Completely agree (5)” (Eskin, 1999a; Eskin, 2004; Eskin, 2013; Eskin et al., 2016b). A principle component analysis with varimax rotation extracted four factors: 1 . Social acceptance $(\alpha=0.90) ; 2$. Helping $(\alpha=0.83) ; 3$. Disapproval of suicidal disclosure $(\alpha=0.77)$;

4. Emotional involvement $(\alpha=0.63)$ that explained $60.73 \%$ of the total variance.

\section{Procedure}

First, a battery of survey was prepared by the principle investigator (M. Eskin). Then, the other researchers were invited via e-mail to join the study. All researchers worked for a university and collected their portion of the data at their institution, but in Jordan and Palestine, data were also collected at a second university. On the first page of the 
Religion, suicide and psychological distress

questionnaire packet, students were told that the study was anonymous. Contact information of the investigator collecting data was provided on the first page of the survey for participants to get in touch and ask possible questions they may have had.

All researchers were requested to only undertake data collection after having received approval from relevant institutional review boards for research ethics. With the exception of Austria where such an approval was formally not necessary according to the relevant legal requirements and regulations, ethical approval was obtained in all study sites. In the United Kingdom, the IRB approved the study first but later the data collection was stopped prematurely by the IRB due to one member's concerns over the possible distress the suiciderelated questions could cause. Almost all of the researchers in this study reported having no legal sanctions against suicidal behavior in their respective country. However, this was not the case for Jordan. According to the Jordanian Penal Code, "The person who attempts suicide will be punished by imprisonment from three months to two years."

\section{Statistical Analyses}

First, the eight religion categories were coded as dummy variables and then, their associations with suicidal behavior and psychological distress were tested by calculating the odds ratios (ORs) by using the chi-squarebinary logistic regression analysis procedure. In calculating the ORs, age, sex and the number of siblings were taken as covariates and hence their effects were controlled for. In the first series of ORs, the control or reference group included participants who reported not affiliating with a religion. In the second series of ORs reported in Table 1, the control or reference group included participants who reported affiliating with all otherny religions and those not affiliating with a religion. Point-biserial correlation coefficients were calculated between strength of religious belief and suicidal behavior, and psychological distress. Two one-way Multivariate Analyses of CoVvariances (MANCOVAs) were performed to explore the relation between religious affiliation (IV) and 
Religion, suicide and psychological distress

suicidal attitudes (DVs) by entering the age and number of siblings as covariates. Scheffé procedure was employed to do multiple comparisons. Finally, Pearson product-moment correlation coefficients were calculated between strength of religious belief and suicidal attitudes.

\section{Results}

\section{Religious affiliation and belief}

The distribution of religious affiliation by country showed that the majority of participants in each country reported affiliating with the dominant religious tradition, with the exception of China, The UK and The USA where the majority reported affiliating with no religion. The majority affiliations by country were as follows: Austria $(n=254$, affiliation with Roman Catholicism $=41,5 \%)$, China $(n=471$, affiliation with no religion $=80.2 \%)$, Iran $(n=1000$, affiliation with Islam $=100 \%)$, Italy $(n=226$, affiliation with Roman Catholicism $=49.1 \%)$, Japan $(n=105$, affiliation with Buddhism $=46.7 \%)$, Jordan $(n=414$, affiliation with Islam $=98.8 \%)$, Palestine $(n=347$, affiliation with Islam $=97.2 \%)$, Saudi Arabia $(n=403$, affiliation with Islam $=97.6 \%)$, Tunisia $(n=470$, affiliation with Islam $=$ 97.3\%), Turkey $(n=450$, affiliation with Islam $=93.0 \%)$, UK $(n=69$, affiliation with no religion $=46.0 \%)$ USA $(n=69$, affiliation with no religion $=28.9 \%)$.

The mean (SD) strength of religious belief ratings on a 7 point scale by country were as follows: Austria 1.7 (1.7), China 1.2 (1.3), Iran 4.2 (1.5), Italy 2.4 (2.1), Japan 1.7 (1.5), Jordan 4.7 (1.1), Palestine 4.7 (1.3), Saudi Arabia 4.7 (1.4), Tunisia 4.6 (1.3), Turkey 4.1 (1.6), UK 2.4 (2.3), and USA 3.1(1.8).

The mean (SD) strength of religious belief ratings by affiliated religion were as follows: Buddhism 2.51 (1.51), Hinduism 3.21 (1.82), Islam 4.48 (1.40), Orthodox 3.02 (1.82), Protestant 2.71 (1.95), Catholic 2.73 (1.85), and other religion 2.88 (2.13). Religious affiliation, suicidal behavior, and psychological distress 
Religion, suicide and psychological distress

The odds ratio (95\% CI) of participants affiliating with any religion having thought of suicide relative to those with no religious affiliation was $0.8277(0.7067-0.9689),\left(\chi^{2}\right.$ Wald $=$ 12.356.30, $\mathrm{df}=1, \mathrm{p}<0.051$. The odds ratio $(95 \% \mathrm{CI})$ of participants affiliating with a religion having attempted suicide relative to those with no religious affiliation was 1.8945 ( 1.0438 2.0358), $\left(\chi^{2}\right.$ Wald $\left.=16.194 .91, \mathrm{df}=1, \mathrm{p}<0.051\right)$. The odds ratios $(95 \% \mathrm{CI})$ of participants affiliating with a religion having scored above the three cut-off points of GHQ-12 relative to those with no religious affiliation were at GHQ-12 $\geq 3,1.4672(1.2650-1.7098),\left(\chi^{2}\right.$ Wald $=$ 59.8625.23, df $=1, \mathrm{p}<0.01$, at GHQ-12 $\geq 4,1.4168(1.2145-1.6594),\left(\chi^{2}\right.$ Wald $=$ 49.8219.27, $\mathrm{df}=1, \mathrm{p}<0.01$,$) and at GHQ-12 \geq 5,1.437(1.2147-2.011 .69), 2\left(\chi^{2}\right.$ Wald $=$ 47.9118.16, df $=1, \mathrm{p}<0.01$.

The associations of religious affiliation to suicidal behavior and psychological distress are shown in Table 1. The table shows that while participants who affiliated with Orthodox religion and those unaffiliated with a religion were significantly more likely to report suicidal ideation; participants who affiliated with Islam were less likely to report suicidal ideation. Participants who affiliated with no religion, Buddhism and Catholicism were significantly less likely to report attempting suicide but those affiliating with Islam were significantly more likely to report attempting suicide. Participants affiliating with Hinduism, Protestantism, Catholicism, other religions and those having been unaffiliated with a religion were significantly less likely to score above the three cut-off points of GHQ-12 $\geq 3$ but participants affiliating with Islam were significantly more likely to score above the three cut-off points of GHQ-12.

Table 1 about here

Religious belief, suicidal behavior, and psychological distress 
Religion, suicide and psychological distress

Table 2 displays the point-biserial correlation coefficients between suicidal behavior and psychological distress and strength of religious belief according to religious affiliation. The strength of religious belief correlates inversely significantly with suicidal ideation in participants affiliating with Hinduism, Islam, Orthodox Christianity, and Catholic religions. A negative correlation was observed between strength of religious belief and suicide attempts in students affiliating with Islam but there were positive correlation between religious belief and suicide attempts in participants affiliating with Catholicism and those affiliating with other religions. The correlation coefficients between religious belief and scoring above the three cut-off points of GHQ-12 were negative and reached significance only in participants affiliating with Islam.

Table 2 about here

Religious affiliation and suicidal attitudes

The means and standard deviations for E-ATSS and E-ATSPS factor scores are presented in Table 3. The one-way MANCOVA on attitudes towards suicide factors produced a significant main effect for religious affiliation, $F_{(7,5419)}=74.30, p<0.0001$. Univariate $F$ tests showed religious affiliation differences on all factors: acceptability of suicide ( $\mathrm{F}=95.29$, $\mathrm{p}<0.0001)$, punishment after death $(\mathrm{F}=553.61, \mathrm{p}<0.0001)$, suicide as a sign of mental illness $(\mathrm{F}=60.65, \mathrm{p}<0.0001)$, communicating psychological problems $(\mathrm{F}=12.28, \mathrm{p}<$ $0.0001)$, hiding suicidal behavior $(\mathrm{F}=59.59, \mathrm{p}<0.0001)$, and open reporting and discussion of suicide $(\mathrm{F}=22.87, \mathrm{p}<0.0001)$.

The one-way MANCOVA on attitudes towards an imagined suicidal friend factors yielded a significant main effect for religious affiliation, $\mathrm{F}_{(7,5419)}=17.92, \mathrm{p}<0.0001$. Univariate $\mathrm{F}$ tests showed significant religious differences on all factors: social acceptance (F 
Religion, suicide and psychological distress

$=7.61, \mathrm{p}<0.0001)$, helping $(\mathrm{F}=12.04, \mathrm{p}<0.0001)$, disapproval of suicidal disclosure $(\mathrm{F}=$ 13.39, $\mathrm{p}<0.0001)$ and emotional involvement $(\mathrm{F}=39.27, \mathrm{p}<0.0001)$ factors.

Table 3 about here

In order to ease the comprehension of our findings, mean E-ATSS and E-ATSPS factor scores were ordered from the lowest to the highest under the respective tables for affiliated religion. The results of post-hoc comparisons with Scheffe tests are given in Table 4.

Table 4 about here

\section{Strength of religious belief and suicidal attitudes}

Table 5 presents the correlation coefficients between the strength of religious belief and attitudes towards suicide and suicidal persons. The highest positive correlation was between punishment after death and participants' strength of religious beliefs, and the highest negative one was between participants' strength of religious beliefs and acceptability of suicide in total sample. For these factors similar patterns were observed for the participants affiliated with Hinduism, Orthodox Christianity, Protestantism, and Catholicism.

Table 5 about here

\section{Discussion}

The present study aimed at testing the effects associations of religious affiliation and the strength of religious belief on to suicidal behavior and attitudes, and psychological distress 
Religion, suicide and psychological distress

in student samples. Scientific investigations have often confirmed showed that being affiliated with a religion is associated with better mental health (Zou et al., 2014) and a lower propensity for suicidal behavior (Dervic et al., 2004; Sisask et al., 2010; Wu et al., 2015). Our results confirm are in line with these findings for suicidal ideation, but disconfirm contrast them for suicide attempts and psychological distress. In this study, participants reporting an affiliation with a religion were found to be at a greater risk for attempting suicide and scoring above the cut-off points of GHQ-12 than those reporting no religious affiliation. These results are in stark contrast to findings from a recent review of 89 studies by Lawrence et al. (2016) who found religion to be a protecting factor against suicide attempts, but not against suicidal ideation. The studies covered in this review were conducted mainly with samples from Western nations. The overwhelming majority of participants from Muslim countries in the present study reported having affiliated with religion. Therefore, the difference between our findings and the findings from Lawrence et al. might be a reflection of social, economic and political conditions in Muslim countries. This is an overview, but does it apply to affiliation with specific religious traditions?

An examination of the associations of affiliation with specific religious traditions to suicidal behavior and psychological distress presents a more nuanced picture (Table 1). While having affiliated with Islam was associated with reduced odds for of contemplating suicide ideation, affiliating with Orthodox religion and not affiliating with a religion were associated with heightened odds of considering suicide. Except for the case of Orthodox Christianity the findings are in line with theoretical expectations. Since no country adhering to Orthodox religion was included in our study, the association between affiliation with Orthodox religion and suicide ideation might be due to minority stress. However, an examination of the associations of religious affiliation to suicide attempts and psychological distress reveals contrasting patterns. Affiliation with Buddhism and Catholicism was associated with reduced 
Religion, suicide and psychological distress

odds of attempting suicide. To our surprise, affiliating with no religion was associated with reduced odds for attempting suicide which is theoretically an inconsistent relation. Another theoretically contradictory finding is the relation between affiliation with Islam and reports of suicide attempts. In line with findings from previous work (Eskin, 1999b; Eskin, Palova, \& Krokavcova, 2014; Eskin, Voracek, Stieger, \& Altinyazar, 2011; Lester, 2006) our findings demonstrate that participants reporting affiliation with Islam have heightened odds of having attempted suicide despite prohibiting attitude of their religion to suicide and they also scored above the three cut-off points of GHQ-12.

Why is affiliation with Islam associated with reduced odds of for contemplating suicide ideation but heightened odds of attempting suicide and higher levels of psychological distress? Two plausible explanations may be offered for these contradictory findings. First, according to Schacter, Guerin, and St Jacques (2011), individuals have a tendency to distort and reconstruct their past memories into meaningful personal narratives. As a result, students from Muslim countries may be reconstructing their own past memories to fit them in with the doctrines of their religious faith. The attempt, however, as a concrete act may not be amenable for distortion. Second, the observed associations might reflect the effects of contextual factors. An overwhelming majority of participants affiliating with Islam are from the Islamic countries; only 61 were from other countries. According to Freedom in the World 2015 report by Freedom House (2015) only Tunisia is classified as free in terms of political rights and civil liberties, Turkey as partly free, and the other Muslim countries included in our study are classified as not free. Religious affiliation has a normative character in Islamic countries. In other words, there is freedom to religion but freedom from religion is limited and involves risks for life and/or social exclusion. Our findings suggest that freedom of choice is essential for religion to exercise its protective function. One can argue that when a belief system is 
Religion, suicide and psychological distress

coerced either by law or by social norms it loses its protective function and becomes a risk factor.

However, when religious belief is taken into account participants' strength of religious belief was associated inversely with suicidal ideation in the total sample, and in the students reported affiliating with Hinduism, Islam, Orthodox Christianity, and Catholicism religions. But, the strength of belief was unrelated to suicide attempts in the total sample but inversely related to attempting suicide in participants affiliating with Islam, and positively in those affiliating with Roman Catholic religion and other religions. Strength of religious belief seems to be protective against psychological distress in Muslim participants but the magnitudes of associations are negligible.

Suicide acceptability is related to broader cultural values and is higher in nonreligious than in religious people (Stack \& Kposowa, 2016). The findings from our study confirm thissupport previous findings. For instance, acceptability of suicide was the highest in students who reported affiliations with Protestantism, no religion, and Catholic religion while it was the lowest in the participants affiliating with Islam, Orthodox Christianity and Buddhism. Participants affiliated with Islam expressing the lowest acceptance for suicide is in line with the findings from Stack and Kposowa, (2011). The highest mean of punishment after death factor scores was seen for the participants affiliating with Islam, Orthodox Christianity, and Hinduism while the lowest scores were in those affiliating with no religion, Catholic religion and Protestantism. The strength of religious belief was inversely related to acceptance of suicide and, positively related to a belief in punishment after death.

An examination of participants' attitudes towards an imagined suicidal friend reveal that the lowest social acceptance of and helping for a suicidal friend were observed in students reported affiliating with Buddhism, other religion and no religion while the highest scores were seen in those affiliating with Orthodox religion, Catholic religion, Hinduism and 
Religion, suicide and psychological distress

Protestantism. Participants affiliating with Orthodox, Catholic and Protestant religions were the least disapproving of a suicidal disclosure in contrast to those affiliating with Buddhism, Islam and no religion. Respondents affiliating with Protestantism, Catholicism and Hinduism displayed least emotional involvement in a fictitious suicidal peer, while those affiliating with Islam, Orthodox religion and with no religion were emotionally most involved in a peer with a suicidal decision. The strength of participant's religious belief was positively related to these attitudinal factors.

Taken together, the currentour findings indicate that the association of religion to suicidal behavior, suicidal attitudes, and psychological distress involve complex issues reflecting effects of both personal and contextual factors. Religious affiliation and the strength of religious belief may be protective against suicidal behaviore and psychological distress for some people in some sociocultural contexts but not so for others in other sociocultural contexts. Recently, Lester and Walker (2017) have showed religiosity to be protective for suicidal ideation in European American students but not in African American students. An unexpected finding from our research is the higher percentages of suicidal attempts and psychological distress in participants who reported affiliating with Islam despite the lowest suicide acceptance in this group. It seems that religiosity is protective for most participants but its protective function seems to be limited for people affiliating with Islam for attempting suicide and to some extent for those affiliating with Orthodox Christianity for suicide ideation. The associations of the strength of religious belief to suicidal behavior are in large part in the expected direction but in participants reported affiliating Catholic religion and other religions, stronger belief was related to more suicide attempts. The effect association of religious belief on to psychological distress was negligible.

\section{Limitations}


Religion, suicide and psychological distress

Although results from this multinational study provide some valuable insights into the relation of religion to suicidal behavior, attitudes and psychological distress, a number of considerations should be taken into account when generalizing our results. First, the university students may not be representative of the general populations of the countries under consideration. Second, the preventative function of religion for mental health may not be as strong in educated segments of populations as it is in the general populations. Third, religious affiliation and strength of religious belief may be too general concepts to examine the effects of religion. Fourth, our findings from this cross-sectional study should not be interpreted in a causal way. Finally, one should bear in mind a possible volunteer bias in our study. Since data were collected from consenting students, it is possible that participants who chose to participate in the study were somewhat different than those who did not consent to be part of the study. For instance, the students who refused to participate may have greater propensity to suicide or psychological distress.

\section{Implications}

Our findings have a number of research and policy implications. First, future research may benefit from examining the association of religious orientation and coping to suicidal phenomena and psychological distress instead of using global variables such as affiliation and strength of belief. Second, more research is needed about suicidal phenomena and psychological well-being in Muslim countries. Third, the influence of minority stress on suicide and psychological distress should be addressed in future research. Next, future research should address social policies or interventions for minimizing adverse effects of minority stress. Finally, sociopolitical measures enhancing not only freedom to religion but also freedom from religion may augment the protective function of religion against suicide and psychological distress in Muslim countries. 
Religion, suicide and psychological distress

\section{References}

Bertolote, J. M., \& Fleischmann, A. (2015). A global perspective in the epidemiology of suicide. Suicidologi, 7, 6-8.

Bonelli, R. M., \& Koenig, H. G. (2013). Mental disorders, religion and spirituality 1990 to 2010: a systematic evidence-based review. Journal of Religion and Health, 52, 657-673.

Boyer, P., \& Bergstrom, B. (2008). Evolutionary perspectives on religion. Annual Review of Anthropology, 37, 111-130.

Colucci, E., \& Martin, G. (2008). Religion and spirituality along the suicidal path. Suicide and Life-Threatening Behavior, 38(2), 229-244.

Dervic, K., Oquendo, M. A., Grunebaum, M. F., Ellis, S., Burke, A. K., \& Mann, J. J. (2004). Religious affiliation and suicide attempt. American Journal of Psychiatry, 161(12), 2303-2308.

Durkheim, E. (1976). The elementary forms of the religious life. New York, NY: George Allen \& Unwin.

Eskin, M. (2013).The effects of individualistic-collectivistic value orientations on non-fatal suicidal behavior and attitudes in Turkish adolescents and young adults. Scandinavian Journal of Psychology, 54, 493-501.

Eskin, M. (1999a). Social reactions of Swedish and Turkish adolescents to a close friend's suicidal disclosure. Social Psychiatry and Psychiatric Epidemiology, 34, 492-497.

Eskin, M. (1999b). Gender and cultural differences in the 12-month prevalence of suicidal thoughts and attempts in Swedish and Turkish adolescents. Journal of Gender, Culture and Health, 4, 187-200.

Eskin, M., Palova, E., \& Krokavcova, M. (2014). Suicidal behavior and attitudes in Slovak and Turkish high school students: A cross-cultural investigation. Archives of Suicide Research, 18(1), 58-73. 
Religion, suicide and psychological distress

Eskin, M., Voracek, M., Stieger, S., \& Altinyazar, V. (2011). A cross-cultural investigation of suicidal behavior and attitudes in Austrian and Turkish medical students. Social Psychiatry and Psychiatric Epidemiology, 46(9), 813-823.

Eskin, M. (2004). The effects of religious versus secular education on suicide ideation and suicidal attitudes in adolescents in Turkey. Social Psychiatry and Psychiatric Epidemiology, 39(7), 536-542.

Eskin M., Sun, J. M., Abuidhail, J., Yoshimasu, K., Kujan, O., Janghorbani, M.,..\&Voracek, M. (2016a). Suicidal behavior and psychological distress in university students: A 12 Nation Study. Archives of Suicide Research, 20, 369-388.

Eskin, M., Kujan, O., Voracek, M., Shaheen, A., Carta, M. G., Sun, J. M., ... \& Tsuno, K. (2016b). Cross-national comparisons of attitudes towards suicide and suicidal persons in university students from 12 countries. Scandinavian Journal of Psychology, 57, 554563.

Freedom House (2015).https://freedomhouse.org/sites/default/files/01152015_FIW_2015_final.pdf. Accessed: 15 April 2015.

Goldberg, D. P., Gater, R., Sartorius, N., Ustun, T. B., Piccinelli, M., Gureje, O., \& Rutter, C. (1997).The validity of two versions of the GHQ in the WHO study of mental illness in general health care. Psychological Medicine, 27(01), 191-197.

Goldberg, D. P., \& Williams, P. (1988). A user's guide to the GHQ.Windsor, NFER Nelson. Inglehart, R., \& Baker, W. E. (2000). Modernization, cultural change, and the persistence of traditional values. American Sociological Review, 65, 19-51.

Joe, S., Romer, D., \& Jamieson, P. E. (2007). Suicide acceptability is related to suicide planning in US adolescents and young adults. Suicide and Life-Threatening Behavior, $37(2), 165-178$. 
Religion, suicide and psychological distress

Kang, P. P., \&Romo, L. F. (2011). The role of religious involvement on depression, risky behavior, and academic performance among Korean American adolescents. Journal of Adolescence, 34(4), 767-778.

Lawrence, R. E., Oquendo, M. A., \& Stanley, B. (2016). Religion and suicide risk: a systematic review. Archives of Suicide Research, 20(1), 1-21.

Lester, D., \& Walker, R. L. (2017). Religiosity is a protective factor for suicidal ideation in European American students but Not in African American students. OMEGA-Journal of Death and Dying, 74(3), 295-303.

Lester, D. (2006). Suicide and Islam. Archives of Suicide Research, 10(1), 77-97.

Nelson, G., Hanna, R., Houri, A., \& Klimes-Dougan, B. (2012). Protective functions of religious traditions for suicide risk. Suicidology Online, 3, 59-71.

Pescosolido, B. (1990). The social context of religious integration and suicide: Pursuing the network explanation. Sociological Quarterly, 31, 337-357.

Pritchard, C., \& Amanullah, S. (2007). An analysis of suicide and undetermined deaths in 17 predominantly Islamic countries contrasted with the UK. Psychological Medicine, 37, 421-430.

Purzycki, B. G., Haque, O., \& Sosis, R. (2014). Extending evolutionary accounts of religion beyond the mind: Religions as adaptive systems. In F. Watts, \& L. P. Turner, (Eds.). (2014). Evolution, Religion, and Cognitive Science: Critical and Constructive Essays. Oxford University Press.

Schacter, D. L., Guerin, S. A., \& St Jacques, P. L. (2011). Memory distortion: an adaptive perspective. Trends in Cognitive Sciences, 15(10), 467-474.

Sisask, M., Värnik, A., Kolves, K., Bertolote, J. M., Bolhari, J., Botega, N. J., ...\& Wasserman, D. (2010). Is religiosity a protective factor against attempted suicide: a cross-cultural case-control study. Archives of Suicide Research, 14(1), 44-55. 
Religion, suicide and psychological distress

Shah, A., \& Chandia, M. (2010). The relationship between suicide and Islam: a cross-national study. Journal of Injury and Violence Research, 2, 93-97.

Stack S (2000). Suicide: A 15-year review of the sociological literature, Part II:

Modernization and social integration perspectives. Suicide and Life-Threatening Behavior 30, 163-176.

Stack, S., \& Kposowa, A. J. (2011). Religion and suicide acceptability: A cross-national analysis. Journal for the Scientific Study of Religion, 50(2), 289-306.

Stack, S., \& Kposowa, A. J. (2016). Culture and Suicide Acceptability: A Cross-National, Multilevel Analysis. The Sociological Quarterly, 57(2), 282-303.

Stark, R., Doyle, D. P., Rushing, L. (1983). Beyond Durkheim: Religion and suicide. Journal for the Scientific Study of Religion 22, 120-131.

Vail, K. E., Arndt, J., \& Abdollahi, A. (2012). Exploring the existential function of religion and supernatural agent beliefs among Christians, Muslims, Atheists, and Agnostics. Personality and Social Psychology Bulletin, 38(10), 1288-1300.

Värnik, P. (2012). Suicide in the world. International Journal of Environmental Research and Public Health, 9(3), 760-771.

Wu, A., Wang, J. Y., \& Jia, C. X. (2015). Religion and completed suicide: a meta-analysis. PloS One, 10(6), e0131715.

Zou, J., Huang, Y., Maldonado, L., Kasen, S., Cohen, P., \& Chen, H. (2014). The efficacy of religious service attendance in reducing depressive symptoms. Social Psychiatry and Psychiatric Epidemiology, 49(6), 911-918. 
Religion, suicide and psychological distress

Table 1. Odds Ratios (OR) between religious affiliation and suicidality and scores above the three cut off points of GHQ-12.

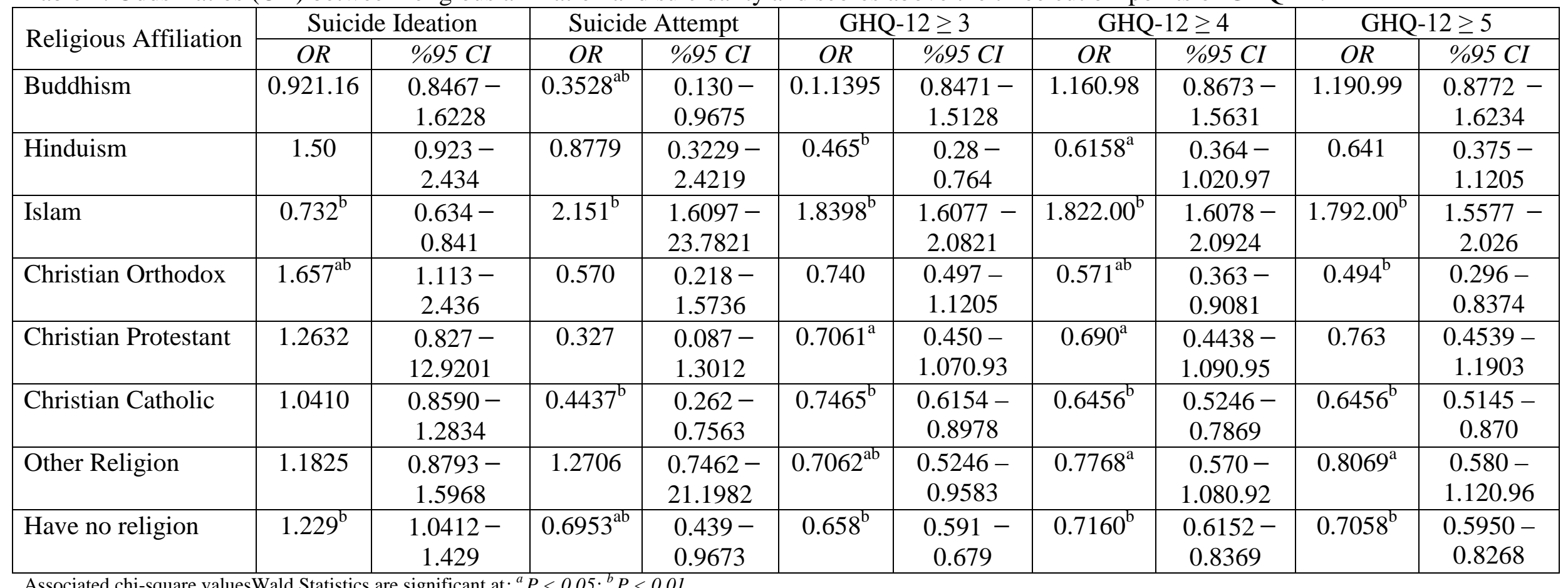

Associated chi-square valuesWald Statistics are significant at: ${ }^{a} P<0.05 ;{ }^{b} P<0.01$ 
Religion, suicide and psychological distress

Table 2. Point-biserial correlation coefficients between strength of religious belief and suicidality and scores above the three cut off points of GHQ-12 by religious affiliation.

\begin{tabular}{|c|c|c|c|c|c|c|c|c|c|c|}
\hline \multirow{2}{*}{ Religious Affiliation } & \multicolumn{2}{|c|}{ Suicide Ideation } & \multicolumn{2}{|c|}{ Suicide Attempt } & \multicolumn{2}{|c|}{ GHQ-12 $\geq 3$} & \multicolumn{2}{|c|}{ GHQ-12 $\geq 4$} & \multicolumn{2}{|c|}{ GHQ-12 $\geq 5$} \\
\hline & $r$ & $D f$ & $r$ & $d f$ & $r$ & $d f$ & $r$ & $d f$ & $r$ & $d f$ \\
\hline Total sample & $-0.14^{\mathrm{b}}$ & 4042 & -0.01 & 4041 & $-0.04^{\mathrm{a}}$ & 4249 & 0.02 & 4249 & 0.02 & 4249 \\
\hline Buddhism & 0.03 & 189 & -0.07 & 189 & -0.05 & 187 & -0.09 & 189 & -0.06 & 187 \\
\hline Islam & $-0.17^{b}$ & 2863 & $-0.10^{b}$ & 2862 & $-0.04^{\mathrm{a}}$ & 3128 & $-0.06^{b}$ & 3128 & $-0.06^{b}$ & 3128 \\
\hline Christian Orthodox & $-0.21^{\mathrm{a}}$ & 109 & -0.06 & 109 & 0.01 & 96 & 0.09 & 96 & 0.05 & 96 \\
\hline Christian Protestant & -0.13 & 97 & 0.02 & 89 & -0.02 & 89 & 0.01 & 89 & 0.01 & 89 \\
\hline
\end{tabular}

$P$ values are significant at: ${ }^{a} P<0.05 ;{ }^{b} P<0.01$, one-tailed. 
Religion, suicide and psychological distress

Table 3. Means and standard deviations of the attitudes towards suicidality factors by participants' religious affiliation

\begin{tabular}{|c|c|c|c|c|c|c|c|c|c|c|c|c|c|c|c|c|}
\hline \multirow[t]{2}{*}{ Attitude factors } & \multicolumn{2}{|c|}{ Buddhism } & \multicolumn{2}{|c|}{ Hinduism } & \multicolumn{2}{|c|}{ Islam } & \multicolumn{2}{|c|}{ No religion } & \multicolumn{2}{|c|}{ Orthodox } & \multicolumn{2}{|c|}{$\begin{array}{c}\text { Protestantis } \\
\mathrm{m}\end{array}$} & \multicolumn{2}{|c|}{ R. Catholic } & \multicolumn{2}{|c|}{$\begin{array}{l}\text { Other } \\
\text { religion }\end{array}$} \\
\hline & $M$ & $S D$ & $M$ & $S D$ & $M$ & $S D$ & $M$ & $S D$ & $M$ & $S D$ & $M$ & $S D$ & $M$ & $S D$ & $M$ & $S D$ \\
\hline \multicolumn{17}{|l|}{ Attitudes to suicide } \\
\hline Acceptability of suicide & 2.07 & 0.80 & 2.11 & 0.98 & 1.62 & 0.81 & 2.35 & 0.91 & 1.78 & 0.76 & 2.37 & 0.90 & 2.14 & 0.85 & 2.12 & 0.92 \\
\hline Punishment after death & 2.31 & 0.77 & 2.33 & 0.96 & 3.86 & 0.97 & 1.84 & 0.79 & 2.51 & 1.00 & 2.19 & 0.90 & 2.04 & 0.86 & 2.31 & 1.00 \\
\hline Suicide as sign of mental illness & 2.67 & 0.97 & 2.82 & 1.11 & 3.43 & 1.25 & 2.45 & 1.01 & 2.96 & 1.13 & 2.76 & 1.00 & 2.78 & 1.10 & 2.77 & 1.06 \\
\hline Communicating problems & 3.73 & 0.66 & 4.01 & 0.70 & 3.73 & 0.90 & 3.66 & 0.83 & 4.12 & 0.74 & 3.85 & 0.65 & 3.99 & 0.70 & 3.82 & 0.85 \\
\hline Hiding suicidal behavior & 2.98 & 0.96 & 2.22 & 0.90 & 2.90 & 1.10 & 2.37 & 0.98 & 2.11 & 0.99 & 2.06 & 0.91 & 1.95 & 0.98 & 2.52 & 1.14 \\
\hline Open reporting \&discussion & 2.70 & 0.85 & 3.18 & 0.94 & 3.06 & 1.06 & 2.83 & 1.07 & 3.18 & 1.07 & 3.22 & 0.90 & 3.47 & 0.84 & 2.85 & 1.05 \\
\hline \multicolumn{17}{|l|}{ Attitudes to suicidal persons } \\
\hline Social acceptance & 3.64 & 0.75 & 3.96 & 0.86 & 3.89 & 0.83 & 3.88 & 0.66 & 4.13 & 0.66 & 3.88 & 0.60 & 3.97 & 0.57 & 3.86 & 0.76 \\
\hline Helping & 3.94 & 0.57 & 4.12 & 0.64 & 4.09 & 0.78 & 4.05 & 0.60 & 4.21 & 0.57 & 4.18 & 0.51 & 4.29 & 0.55 & 3.96 & 0.68 \\
\hline Disclosure disapproval & 2.91 & 0.72 & 2.59 & 0.95 & 2.79 & 0.83 & 2.58 & 0.76 & 2.36 & 0.74 & 2.46 & 0.64 & 2.37 & 0.71 & 2.68 & 0.73 \\
\hline Emotional involvement & 3.05 & 0.89 & 3.00 & 0.97 & 3.46 & 0.89 & 3.10 & 0.90 & 3.16 & 0.95 & 2.63 & 0.83 & 2.99 & 0.94 & 3.03 & 0.97 \\
\hline
\end{tabular}

E-ATSS factor scores from the lowest to the highest:

Acceptability of suicide: Islam, Orthodox, Buddhism, Hinduism, Other religion, Catholicism, No religion, Protestantism

Punishment after death: No religion, Catholicism, Protestantism, Buddhism, Other religion, Hinduism, Orthodox, Islam

Suicide as sign of mental illness: No religion, Buddhism, Protestantism, Other religion, Catholicism, Hinduism, Orthodox, Islam

Communicating problems: No religion, Buddhism, Islam, Other religion, Protestantism, Catholicism, Hinduism, Orthodox

Hiding suicidal behavior: Catholicism, Protestantism, Orthodox, Hinduism, No religion, Other religion, Islam, Buddhism

Open reporting \& discussion: Buddhism, No religion, Other religion, Islam, Hinduism, Orthodox, Protestantism, Catholicism

E-SRSPS factor scores from the lowest to the highest:

Social acceptance: Buddhism, Other religion, No religion, Protestantism, Islam, Hinduism, Catholicism, Orthodox

Helping: Buddhism, Other religion, No religion, Islam, Hinduism, Protestantism, Orthodox, Catholicism

Disclosure disapproval: Orthodox, Catholicism, Protestantism, No religion, Hinduism, Other religion, Islam, Buddhism

Emotional involvement: Protestantism, Catholicism, Hinduism, Other religion, Buddhism, No religion, Orthodox, Islam 
Religion, suicide and psychological distress

Table 4. Post-hoc comparisons of country E-ATSS factor scores* (above the diagonal) and E-SRSPS factor scores** (below the diagonal) with Scheffe tests

\begin{tabular}{|l|l|l|l|l|l|l|l|l|}
\hline \multicolumn{1}{|c|}{ Religions } & Buddhism & Hinduism & Islam & No religion & Orthodox & Protestantism & R. Catholic & $\begin{array}{c}\text { Other } \\
\text { religion }\end{array}$ \\
\hline 1. Buddhism & & 5 & $1,2,3,6$ & $1,2,5$ & $4,5,6$ & 5,6 & 5,6 & 5 \\
\hline 2. Hinduism & & & $1,2,3,5$ & 2 & & & \\
\hline 3. Islam & 1,4 & 4 & & $1,2,3,5,6$ & $2,3,4,5$ & $1,2,3,5$ & $1,2,3,4,5$, & $1,2,3,5$ \\
\hline 4. No religion & 1,3 & & 3,4 & & $1,2,3,4$ & 4 & $1,2,3,4,5$, & 2 \\
\hline 5. Orthodox & 1,3 & & 3 & & & 1 & 1,2 & \\
\hline 6. Protestantism & 3,4 & & 3,4 & 4 & 4 & & & \\
\hline 7. R. Catholic & $1,2,3$ & & $2,3,4$ & 2,3 & & & & 5,6 \\
\hline 8. Other religion & & & 4 & & & & & \\
\hline
\end{tabular}

* E-ATSS factors:

1. Acceptability of suicide, 2. Punishment after death, 3. Suicide as a sign of mental illness, 4. Communicating psychological problems, 5. Hiding suicidal behavior, 6. Open reporting and discussion of suicide.

** E-SRSPS factors:

1. Social acceptance, 2.Helping, 3. Disclosure disapproval, 4. Emotional involvement 
Religion, suicide and psychological distress

Table 5.Correlation coefficients between attitudes towards suicidality and participants' strength of religious beliefs.

\begin{tabular}{|c|c|c|c|c|c|c|c|c|c|c|c|c|c|c|c|c|}
\hline \multirow[t]{2}{*}{ Attitude factors } & \multicolumn{2}{|c|}{ Total sample } & \multicolumn{2}{|c|}{ Buddhism } & \multicolumn{2}{|c|}{ Hinduism } & \multicolumn{2}{|c|}{ Islam } & \multicolumn{2}{|c|}{ Orthodox } & \multicolumn{2}{|c|}{$\begin{array}{c}\text { Protestanti } \\
\text { sm }\end{array}$} & \multicolumn{2}{|c|}{ R. Catholic } & \multicolumn{2}{|c|}{$\begin{array}{l}\text { Other } \\
\text { religion }\end{array}$} \\
\hline & $r$ & $d f$ & $R$ & $d f$ & $r$ & $d f$ & $r$ & $d f$ & $r$ & $d f$ & $r$ & $d f$ & $r$ & $d f$ & $r$ & $d f$ \\
\hline \multicolumn{17}{|l|}{ Attitudes to suicide } \\
\hline Acceptability of suicide & $-0.38^{\mathrm{c}}$ & 5572 & -0.09 & 190 & $-0.50^{c}$ & 75 & $-0.23^{\mathrm{c}}$ & 3145 & $-0.37^{\mathrm{c}}$ & 109 & $-0.40^{\mathrm{c}}$ & 97 & $-0.39^{c}$ & 512 & $-0.17^{\mathrm{a}}$ & 202 \\
\hline Punishment after death & $0.61^{\mathrm{c}}$ & 5572 & -0.03 & 190 & $0.43^{\mathrm{c}}$ & 75 & $0.22^{\mathrm{c}}$ & 3145 & $0.57^{\mathrm{c}}$ & 109 & $0.63^{\mathrm{c}}$ & 97 & $0.47^{\mathrm{c}}$ & 512 & $0.34^{\mathrm{c}}$ & 202 \\
\hline Suicide as sign of mental illness & $0.26^{\mathrm{c}}$ & 5572 & -0.06 & 190 & -0.12 & 75 & $0.07^{\mathrm{c}}$ & 3145 & 0.10 & 109 & -0.00 & 97 & -0.05 & 512 & 0.02 & 202 \\
\hline Communicating problems & $0.10^{\mathrm{c}}$ & 5572 & $0.14^{\mathrm{a}}$ & 190 & 0.23 & 75 & $0.15^{\mathrm{c}}$ & 3145 & $0.21^{\mathrm{a}}$ & 109 & 0.15 & 97 & $0.12^{\mathrm{b}}$ & 512 & 0.09 & 202 \\
\hline Hiding suicidal behavior & $0.17^{\mathrm{c}}$ & 5572 & -0.10 & 190 & -0.05 & 75 & 0.03 & 3145 & -0.10 & 109 & 0.03 & 97 & 0.00 & 512 & 0.08 & 202 \\
\hline Open reporting \&discussion & $0.05^{\mathrm{c}}$ & 5572 & -0.06 & 190 & 0.15 & 75 & 0.00 & 3145 & -0.06 & 109 & -0.14 & 97 & -0.01 & 512 & -0.04 & 202 \\
\hline \multicolumn{17}{|l|}{ Attitudes to suicidal persons } \\
\hline Social acceptance & $0.03^{\mathrm{a}}$ & 5572 & $0.24^{\mathrm{b}}$ & 190 & 0.06 & 75 & 0.01 & 3145 & $0.22^{\mathrm{a}}$ & 109 & 0.00 & 97 & $0.14^{\mathrm{b}}$ & 512 & 0.14 & 202 \\
\hline Helping & $0.05^{\mathrm{b}}$ & 5572 & $0.22^{\mathrm{b}}$ & 190 & -0.17 & 75 & $0.06^{\mathrm{b}}$ & 3145 & 0.09 & 109 & -0.14 & 97 & $0.09^{\mathrm{a}}$ & 512 & 0.01 & 202 \\
\hline Disclosure disapproval & $0.13^{\mathrm{c}}$ & 5572 & $-0.16^{\mathrm{a}}$ & 190 & 0.17 & 75 & $0.09^{c}$ & 3145 & 0.14 & 109 & 0.14 & 97 & 0.07 & 512 & -0.09 & 202 \\
\hline Emotional involvement & $0.19^{\mathrm{c}}$ & 5572 & 0.06 & 190 & 0.17 & 75 & $0.09^{c}$ & 3145 & $0.25^{\mathrm{b}}$ & 109 & 0.12 & 97 & $0.22^{\mathrm{c}}$ & 512 & -0.05 & 202 \\
\hline
\end{tabular}

$P$ values are significant at: ${ }^{a} P<0.05 ;{ }^{b} P<0.01 ;{ }^{c} P<0.001$. 